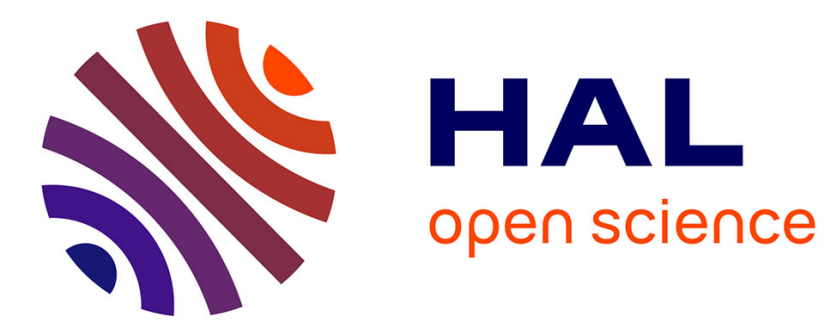

\title{
Measurement of Net Ion Fluxes Using Ion-Selective Microelectrodes at the Surface of Ectomycorrhizal Roots
}

\author{
Anthony Gobert, Claude C. Plassard
}

\section{To cite this version:}

Anthony Gobert, Claude C. Plassard. Measurement of Net Ion Fluxes Using Ion-Selective Microelectrodes at the Surface of Ectomycorrhizal Roots. Symbiotic Fungi: Principles and Practice, 18, Springer, 2009, Soil Biology, 10.1007/978-3-540-95894-9_5 . hal-02816104

\section{HAL Id: hal-02816104 \\ https://hal.inrae.fr/hal-02816104}

Submitted on 6 Jun 2020

HAL is a multi-disciplinary open access archive for the deposit and dissemination of scientific research documents, whether they are published or not. The documents may come from teaching and research institutions in France or abroad, or from public or private research centers.
L'archive ouverte pluridisciplinaire HAL, est destinée au dépôt et à la diffusion de documents scientifiques de niveau recherche, publiés ou non, émanant des établissements d'enseignement et de recherche français ou étrangers, des laboratoires publics ou privés. 


\title{
Chapter 5 \\ Measurement of Net Ion Fluxes Using \\ Ion-Selective Microelectrodes at the Surface of Ectomycorrhizal Roots
}

\author{
A. Gobert and C. Plassard
}

\subsection{Introduction}

Ion-selective microelectrodes are used to measure ion gradients across membranes, but they can serve various purposes (Newman 2001). They are used in animal, plant and even bacteria studies (McClure et al. 1990; Shabala et al. 2001; Kang et al. 2003). Two different kinds of ion-selective microelectrodes can be produced: microelectrodes for net flux measurements - non-invasive - (Gobert and Plassard 2002) and microelectrodes for intracellular studies — impalement needed (Miller et al. 2001). Although we have knowledge of double-barrelled microelectrodes for intracellular studies of ectomycorrhizas, this chapter is aimed at describing the technique of ion flux measurement outside the tissues in plants and ectomycorrhizal roots.

This technique applied to ion fluxes originating from plants is not widely used and arose in the late 1980s and early 1990s (Newman et al. 1987; Henriksen et al. 1990). Ion-selective microelectrodes give access to net flux measurements originating from a few micrometers at the surface of the root of an undisturbed plant. The technique can be easily applied to study the effects of gene mutation or differences between ecotypes or fungal strains. In addition, the effect of biotic (phytotoxins, myc factors) and abiotic factors (temperature, osmotic stress) can be assessed. The technique has been applied on plants for cation measurements such as $\mathrm{K}^{+}, \mathrm{H}^{+}, \mathrm{NH}_{4}{ }^{+}$and $\mathrm{Ca}^{2+}$ (Kochian et al. 1989; McClure et al. 1990; Huang et al. 1992; Henriksen et al. 1992) and anion measurements such as $\mathrm{NO}_{3}{ }^{-}$(McClure et al. 1990). In our laboratory, we have developed this method to quantify net $\mathrm{H}^{+}, \mathrm{K}^{+}$and

\footnotetext{
A. Gobert and C. Plassard $(\bowtie)$

UMR 1222 Eco\&Sols, INRA-IRD-SupAgro, Bat 12, 2, place Viala, 34060 Montpellier, cedex, 01 France

e-mail: plassard@supagro.inra.fr
} 
$\mathrm{NO}_{3}{ }^{-}$fluxes occurring along the roots of woody species and ectomycorrhizal roots (Gobert and Plassard 2002, 2007; Plassard et al. 2002). In this chapter, we will present the theory and the practice behind the microelectrodes, followed by some examples of local net flux measurements.

\subsection{Principle of Ion Activities Measurement with Ion-Selective Microelectrodes}

\subsubsection{What Is an Ion-Selective Microelectrode?}

In our system, ion-selective microelectrodes are made from a glass capillary which has been pulled and silanized. Then the tip is filled with a minimal amount of a liquid membrane (the cocktail) that contains the ionophore selective for an ion. Finally, the remainder of the capillary is filled with a saline solution (the back solution) (Fig. 5.1). The microelectrodes are then connected to an amplifier via a silver wire to measure the electrochemical potential difference of the studied ion in the solution, setting out and inside the microelectrode across the cocktail. Voltage values given by the amplifier are only due to the ion under study because the cocktails are highly specific.

The main component of the cocktail solution is a complexing agent (ligand) responsible for ion selectivity. This agent belongs to the category of ionophores, comprising ion channels and transporters, although only ion transporters are used to make the cocktail (Ammann 1986). The transporter, which is dissolved in an organic phase, diffuses throughout the membrane as complexes with the ion under study, thus carrying the ion from the outside solution (the measuring solution) into the inside solution (the back solution of the microelectrode).

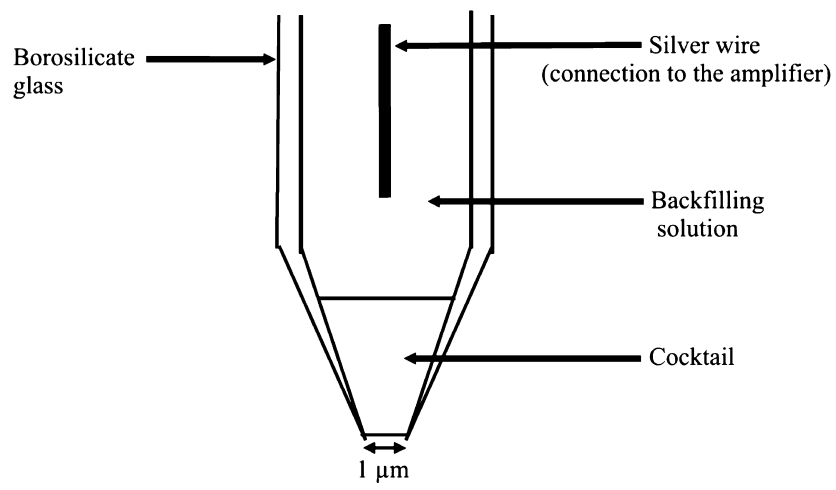

Fig. 5.1 Schematic representation of an ion-selective microelectrode, with the cocktail containing the ionophore at the tip and the backfilling solution creating the electric connection with the silver chloride wire 
The back solution is a salt solution containing chloride ions $\left(\mathrm{Cl}^{-}\right)$and the ion under study. Its concentration should be very high to avoid possible variation and to minimize possible errors in ion activity determinations. Generally, $\mathrm{KCl}$ is used, but it is possible to use another salt if anion and cation mobilities are as close as possible.

The measurement of the electrochemical potential difference requires movements of small amounts of electrical charges between the aqueous phase (back solution) and the metal phase (the silver wire) constituting an electrode. It is necessary for the charge movement to occur through a reversible, reproducible and dominant chemical reaction at the interface solution/solid metal. The chemical reaction which is generally used is the one occurring at the interface silver/silver chloride, which is as follows:

$$
\operatorname{AgCl}(\mathrm{s})+\mathrm{e}^{-} \rightarrow \operatorname{Ag}(\mathrm{s})+\mathrm{Cl}^{-}
$$

This reaction supplies a good electrical contact between the silver wire and the solution (Thain 1995). As indicated by the equation given above, the electrical potential measured with the silver/silver chloride electrode will depend on the concentration of available chloride anions in the solution. It is therefore important that this concentration remains constant during the experiment.

\subsubsection{Expression of the Voltage Difference Across the Cocktail}

The system has two distinct compartments: the internal compartment (back solution) with a concentration $C_{\mathrm{i}}$ and the external compartment (the solution to be measured) with a concentration $C_{\mathrm{e}}$ In each compartment, the ion electrochemical potential will be

$$
\mu=\mu^{\circ}+V^{\circ}\left(P_{\mathrm{a}}-P^{\circ}\right)+R T \ln (C \gamma)+M g h+n F V
$$

with $\mu$ electrochemical potential, $\mu^{\circ}$ reference electrochemical potential, $V$ voltage, $P_{\mathrm{a}}-P^{\circ}$ pressure difference, $R$ constant of perfect gas, $T$ temperature, $C$ concentration, $\gamma$ activity coefficient, $g$ earth force coefficient and $n$ ion valence. In addition, we know that at equilibrium the electrochemical potential of the ion has the same value in both compartments; thus,

$$
\mu_{\mathrm{i}}=\mu_{\mathrm{e}}
$$

and

$$
\Delta \mu=\mu_{\mathrm{i}}-\mu_{\mathrm{e}}=0
$$


After simplification of (5.3) (for detail of calculation, see Ammann 1986), we obtain Nernst's equation, which gives the voltage difference across the two compartments as a function of the concentrations:

$$
\Delta V=(R T / n F) \ln \left(C_{\mathrm{e}} / C_{\mathrm{i}}\right)
$$

Therefore, the ideal relationship between electrode output $(\mathrm{mV})$ and the activity $\left(a_{\mathrm{i}}\right)$ of the ion under study (i) is log-linear, and should give an ideal slope of 59 $\mathrm{mV}$ per decade change in the activity of a monovalent ion at $25^{\circ} \mathrm{C}$ when the electrode is calibrated in the appropriate solution. However, in practice, the situation is more complicated than this, because no ion-selective electrode has ideal selectivity for one particular ion, and under most conditions there is more than one ion present in the sample solution. Hence, contributions to the overall electro-motive force (EMF) made by each interfering ion, $J$, must be taken into account (Ammann 1986). Major interfering ions for each selective membrane are given in the Fluka catalogue. If the measuring solution contains known interfering ions, the selectivity coefficient of the membrane should be determined during the calibration step. For that, the fixed interference method is most commonly used to calculate the selectivity coefficient, and it is the method recommended by the International Union of Pure and Applied Chemistry (Ammann 1986). However, very simplified solutions, with a minimal concentration of interfering ions, can be used when measuring ion fluxes at the root surface, thus minimizing the lack of sensitivity of a given membrane, if it exists.

\subsection{Principle of Flux Measurement}

\subsubsection{Expression of Local Diffusion Flux in a Solution}

If a coloured solution is poured very gently into a non-coloured solution, we will see the delimited surface between the two liquids which disappears with time. This is due to the diffusion of the coloured solution into the non-coloured one, and vice versa. Similarly, across a transversal section, there are always particles running in opposite directions. The movement of these particles occurs in both directions and will stop only when the mixing is perfect. However, the diffusion vector $J$ is orientated towards the decreasing potentials. The equation that describes the diffusion is Fick's law:

$$
J=-D\left(C_{1}-C_{0}\right) /\left(x_{1}-x_{0}\right)=-D \Delta C / \Delta x,
$$

with $J$ local flux of diffusion, $D$ diffusion coefficient of the ion of interest, $C_{1}$ ion concentration at the distance $x_{1}, C_{0}$ ion concentrations at the distance $x_{0}$. 


\subsubsection{Estimation of Ion Fluxes at the Root Surface}

When a root is placed in a solution where ions are moving by diffusion and where the coordinates of radial symmetry apply (Fig. 5.2), the net radial ion flux is given by the following equation (Newman et al. 1987; Henriksen et al. 1992):

$$
J=\frac{2 \pi D\left(C_{2}-C_{1}\right)}{\ln \left(r_{2} / r_{1}\right)} \quad\left(\text { in } \mathrm{mmol} \mathrm{cm} \mathrm{c}^{-1} \mathrm{~s}^{-1}\right)
$$

with $D$ diffusion coefficient $\left(\mathrm{cm}^{2} \mathrm{~s}^{-1}\right), C_{1}$ concentration at a radial distance $r_{1}, C_{2}$ concentration at a radial distance $r_{2}, r_{1}$ and $r_{2}$ radial distances from the cylinder centre.

The ion flux crossing the transversal root section of area $A$ and with a root density $\rho$ (that we take by default equal to 1 ) for $1 \mathrm{~h}$ will be

$$
\begin{gathered}
J=\frac{k(2 \pi D / A \rho)\left(C_{2} / C_{1}\right)}{\ln \left(r_{2} / r_{1}\right)}, \\
J=\frac{k\left(2 D / r^{2}\right)\left(C_{2} / C_{1}\right)}{\ln \left(r_{2} / r_{1}\right)} .
\end{gathered}
$$

Finally, we obtain the following equation used to calculate the ion flux occurring at the root surface:

$$
J=\frac{k\left(2 D / r^{2}\right)\left(C_{2} / C_{1}\right)}{\ln \left[\left(d_{2}+r\right) /\left(d_{1}+r\right)\right]} \quad\left(\text { in } \mu \mathrm{mol} g^{-1} \text { root } \mathrm{fwt}^{-1} \mathrm{~h}^{-1}\right)
$$

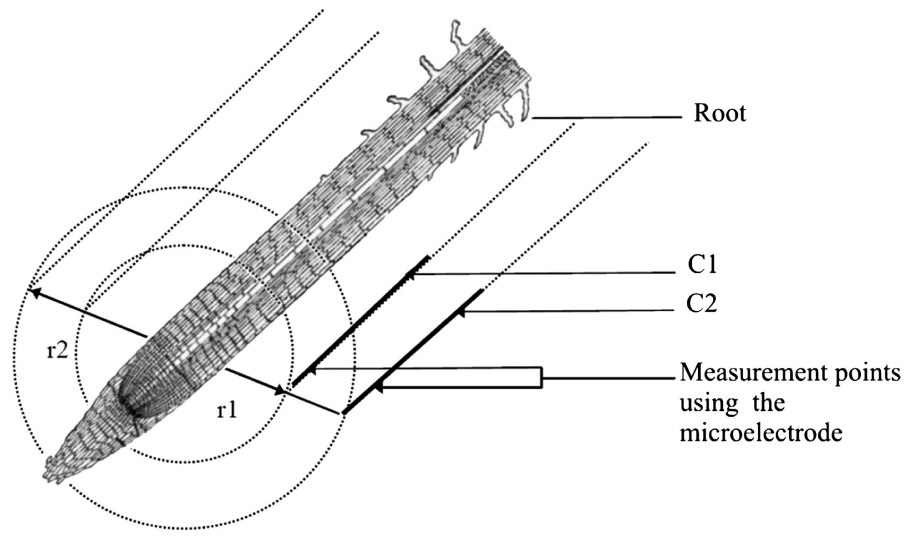

Fig. 5.2 Schematic representation of the radial symmetry of ion diffusion occurring in the solution at the surface of the root 
with $k$ coefficient for unit conversion, $r$ root radius, $d_{1}$ and $d_{2}$ measuring distances from the root surface (Fig. 5.2).

\subsection{Equipment and Microelectrode Fabrication}

\subsubsection{Experimental Set-up}

\subsubsection{Electric Circuit}

The use of ion-selective microelectrodes needs a controlled environment against electric, electromagnetic and vibration interference, because the measurements are in the pico-Amp value range. The measurements are realised in a Faraday cage on an antivibration table in order to reduce background noise. The measurement set-up is composed of an electric circuit with several resistances (Fig. 5.3). The main resistance is included in the high impedance amplifier (A) $(1,015 \Omega)$. The potential difference between the flowing solution and the backfilling solution of the microelectrode is the generator. The microelectrode $\left(\mathrm{M}_{\mathrm{e}}\right.$, whose resistance is $\left.R_{\mathrm{e}}\right)$ is fixed on a headstage giving a gain of $0.0001 \mathrm{M}$ (Rpa) before entering the amplifier with resistance $R_{\mathrm{a}}$. The circuit is closed by the $\mathrm{pH}$ meter electrode, which acts as a reference electrode $\left(\mathrm{M}_{\mathrm{ref}}\right)$.

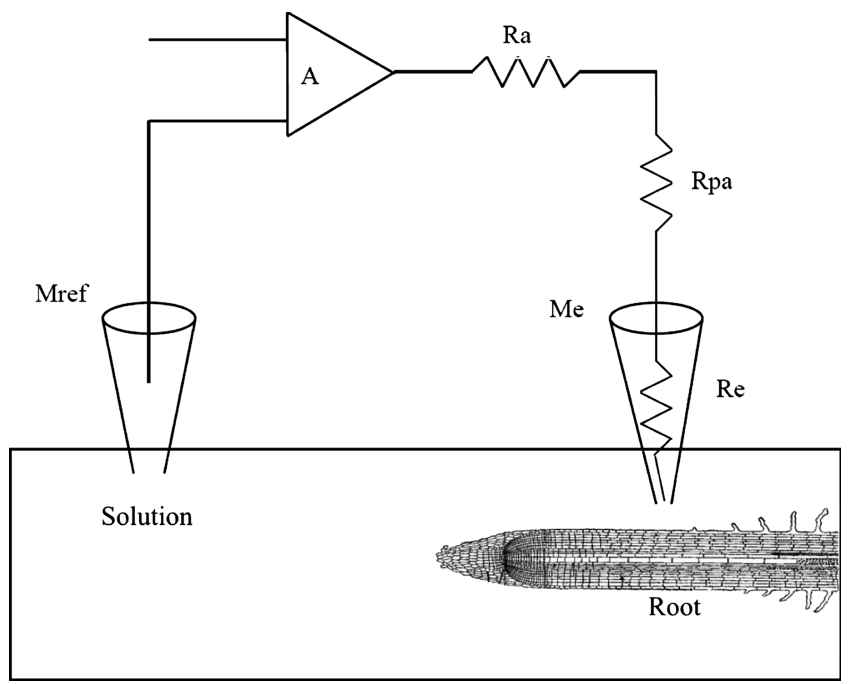

Fig. 5.3 The measurement set-up of an ion-selective microelectrode 


\subsubsection{Equipment Set-up}

As described above, specific equipment is needed in order to carry out the flux measurements. Indeed, the current throughout the cocktail is very small and a high impedance electrometer amplifier and background noise protection are needed.

\subsubsection{Equipment Needed}

Faraday cage sitting over an "antivibration" table (home-made)

Microscope (e.g. $\times 180$, from Ealing, http://www.ealingcatalog.com/) with a fitted live camera fixed on the table (i.e. from Sony, http://www.sonybiz.net/)

Manual micromanipulators (where the microelectrode holders are fixed, e.g. from Narishige, http://www.narishige.co.jp/)

Computer-assisted stage (where the measuring chamber is placed; e.g. from Ealing) Amplifiers (e.g. Axoprobe-1A, Axon Instruments, now available at http://www. moleculardevices.com/)

Interface (e.g. MacLab/8e, ADInstruments, http://www.adinstruments.com/)

Computer with acquisition software (e.g. Chart V3.3.7, ADIntruments)

Monitor (live feed from the camera fixed to the microscope; e.g. Sony)

$\mathrm{pH}$ meter and electrode (e.g. Metrohm)

Optic fibre light source

Bottles and tubing for the solution entrance and exit from the chamber

The set-up is virtually described in Fig. 5.4, with equipment placed inside and outside of the Faraday cage.

\subsubsection{Inside the Faraday Cage}

On the "antivibration" table, the microscope and the computer-assisted stage are the main features. A camera is fixed at the back of the microscope. The table supports some posts with clamps to fix the microelectrode holders (HS-2 Headstage, Axon Instruments, $0.0001 \mathrm{M}$ gain). All the cables are earthed.

The chamber holding the root is mounted on the computer-assisted stage. It is designed so that the root system can be continuously perfused with the experimental nutrient solution throughout the measurement. The waste solution coming out of the chamber is collected in a plastic beaker in the cage.

\subsubsection{Outside the Faraday Cage}

All the electronic equipment is outside the cage. The electric signal coming from the electrodes is sent to a high-impedance electrometer amplifier $(1,015 \Omega$ ) (Axon Instruments, Inc. 1993). Then, the electrometer output is directed via an A/D 


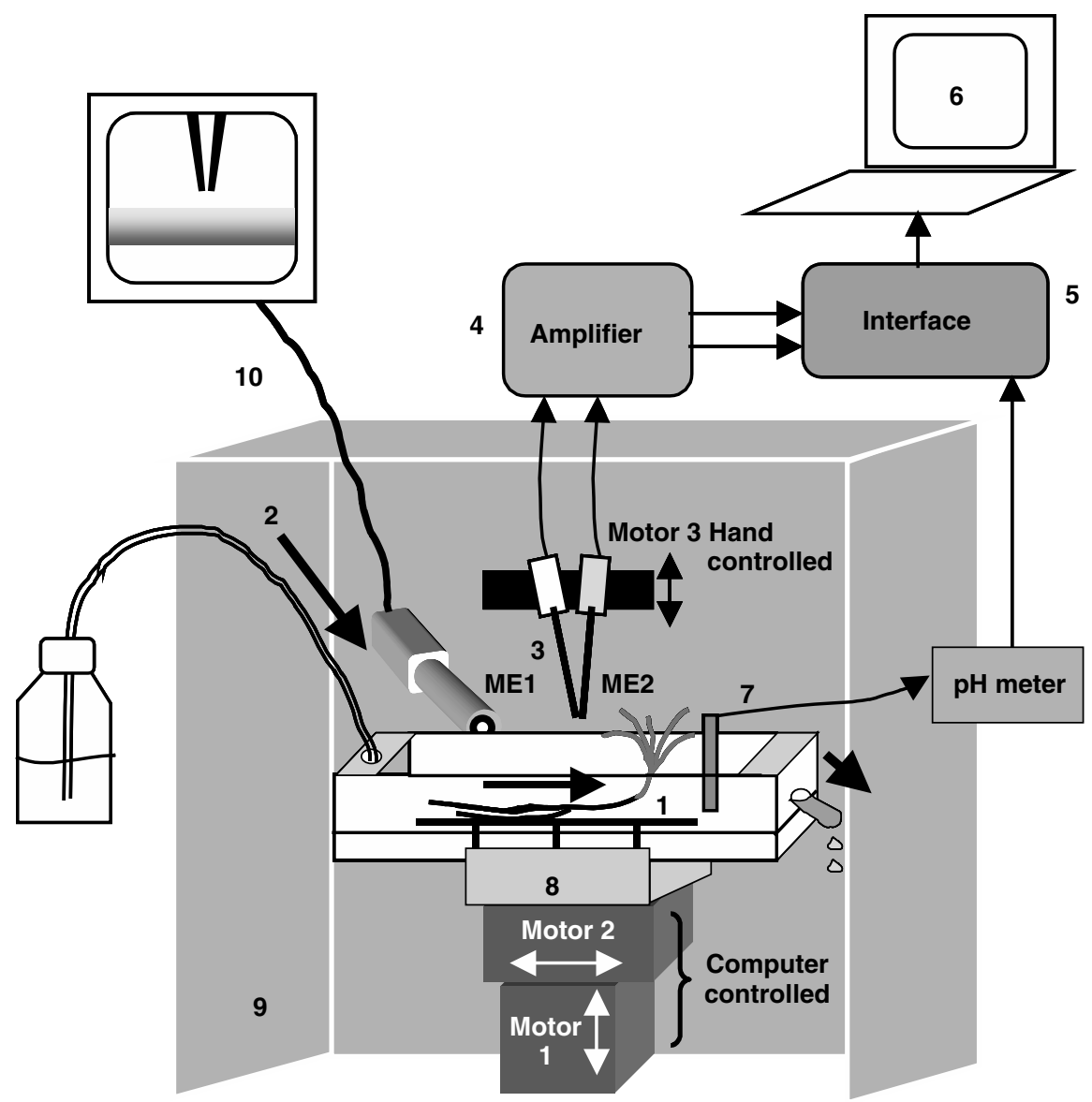

Fig. 5.4 Experimental set-up for continuous monitoring of ion fluxes using ion-selective microelectrodes: (1) Intact plant in a perspex cuvette, (2) flowing solution, (3) ion-selective microelectrodes plugged in headstages and moved by a hand-controlled motor, (4) amplifier, (5) interface (McLab), (6) computer (MacIntosh), (7) combined pH-macroelectrode, (8) mobile plate moving the cuvette using computer-controlled motors, (9) Faraday cage, (10) monitor connected to the camera

converter to a computer. The circuitry is terminated through a $\mathrm{pH}$ meter submerged in the chamber.

In addition, the camera monitor and the light supply are outside the cage.

Finally, the perfusing solution is made just prior to use (the $\mathrm{pH}$ is carefully set in order to avoid discrepancy between the different concentrations). The solution is bubbled with decarbonated air (air going though soda lime and boiled water) to obtain an $\mathrm{HCO}_{3}^{-}$free solution. The bottles of solution stand outside the cage at a higher position than the chamber, and the liquid moves with gravity towards the chamber (into tubing with a tap). The flow is reduced using a low-diameter needle plunged into the chamber. 


\subsubsection{Making the Microelectrodes}

\subsubsection{Pulling of Glass Micropipettes}

In our set-up, the microelectrodes are made from borosilicate glass. The borosilicate glass tubes have to be pulled into two equal pieces to create the microelectrodes.

\subsubsection{Equipment Needed}

Borosilicate capillaries (GC150F-10, Clark Electromedical Instruments, Pangbourne, UK) two-step puller (provider).

One extremity of the borosilicate tube is fixed at each side of the puller, the bottom mortar being lifted.

Then, a two-step protocol is applied to produce microelectrodes of the desired size (1-2 $\mu \mathrm{m}$ diameter in our case). An estimate of the tip size of the microelectrode is determined by measuring its electrical resistance when filled with $3 \mathrm{M} \mathrm{KCl}$. Smaller tips have higher resistances than larger tips, but the dimensions of the microelectrodes are usually a compromise between obtaining a stable membrane potential and a good calibration response (detection limit).

\subsubsection{Internal Silanization of the Pulled Borosilicate Tube or Microelectrode}

The inside of the glass micropipettes must be given a hydrophobic coating, to allow the formation of a high resistance seal between the glass and the hydrophobic ion-selective membrane.

\subsubsection{Equipment Needed}

Fume hood (for all silanizing agent and solvent use)

Oven reaching $180^{\circ} \mathrm{C}$ (in a aerated area or in the fume hood)

Micropipette holder (home-made in our case, Fig. 5.5)

$100-\mu l$ glass syringe

Silanizing agent (e.g. $N, N$-dimethyltrimethylsilylamine or tributylchlorosilane, from Fluka)

Tetrahydrofurane (for rinsing the syringe after silicone use)

First, carefully place the extremity of the microelectrodes in the hole in the holder (tip to the sky). The holder has an inside cavity where the silanizing agent can be poured; this cavity is linked only to the inside of the microelectrodes. When placing 


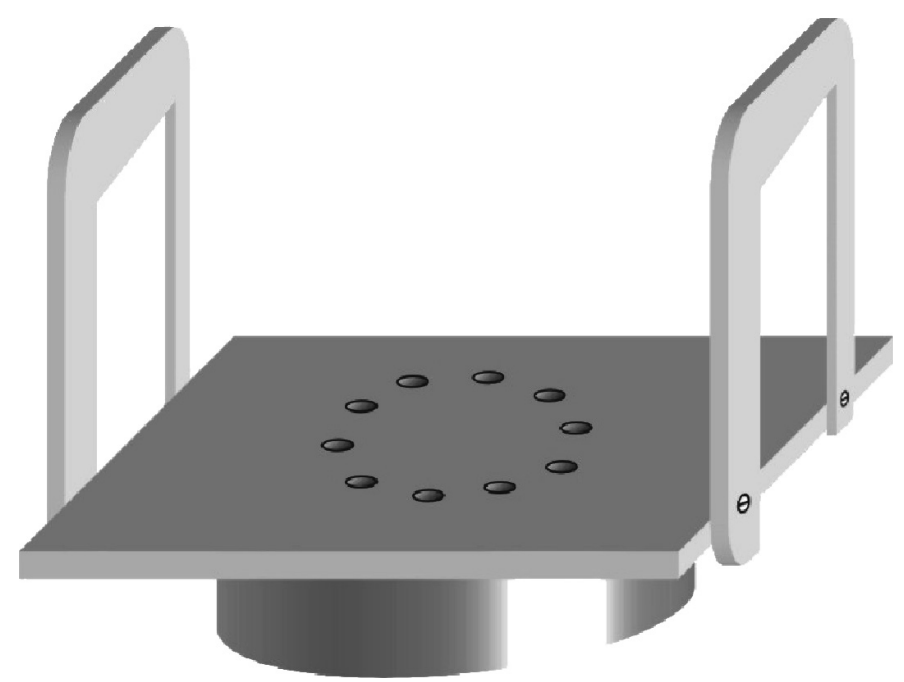

Fig. 5.5 Home-craft microelectrode handler for silanization of the internal surface of the microelectrodes

the microelectrodes, one hole remains empty of microelectrode in order to pour the silicon. It may be closed with a nail. The holder is then placed for $1 \mathrm{~h}$ into an oven set at $150^{\circ} \mathrm{C}$ in order to get rid of any traces of humidity that could interfere with the process of silanization. In the fume hood, $40 \mu \mathrm{l}$ of silanizing agent is sucked into a glass syringe. The holder is taken from the oven to the fume hood and the siliconbased compound is injected into the hole by lifting the nail with forceps (beware the holder is very hot). The hole is immediately sealed with the nail once again, and the holder placed into the oven set at $130^{\circ} \mathrm{C}$ for $1 \mathrm{~h}$. The silicone vapours condense on the wall of the pipettes. The holder can be removed from the oven and left to cool on the bench.

\subsubsection{Backfilling the Pipette}

The microelectrodes are filled at the tip with the cocktail containing the ion-selective ionophore and then $24 \mathrm{~h}$ later backfilled with an aqueous solution. The microelectrodes are then ready for use.

\subsubsection{Equipment Needed}

Dissecting microscope

Flame-elongated borosilicate tubes with very thin diameter in order to rich the tip of the microelectrode from its other end 
10-ml syringe extended with a silicon-based tube whose inner diameter matches the outer diameter of the borosilicate tubes

Ion-selective cocktails (ready-to-use, e.g. Fluka or home-made)

Salt solution $\left(\mathrm{KNO}_{3}, \mathrm{KCl}, \ldots\right)$, ultrapure water and $\mathrm{pH}$ meter

In our laboratory, we use $\mathrm{H}^{+}, \mathrm{K}^{+}$and $\mathrm{NO}_{3}{ }^{-}$microelectrodes. $\mathrm{H}^{+}$microelectrodes are filled with a ready-to-use cocktail (Fluka 95297), as are our $\mathrm{K}^{+}$microelectrodes (Fluka 60398). $\mathrm{NO}_{3}{ }^{-}$microelectrodes are filled with a home-made cocktail comprising MTDDA NO${ }_{3}^{-}(8.3 \%)$, MTPPB (1.4\%) and NPOE (90.3\%).

These cocktail solutions are sucked up into the rod from the flame-elongated tube with the syringe (the borosilicate tube being connected to the silicon base tube). You need to pull the syringe hard to fill only a few micrometers of the rod. This rod is then inserted into the extremity of the microelectrode (it is better to use a magnifier) and moved towards the tip of the microelectrode. When it has reached the tip, push the syringe to expel a minimum amount of cocktail into the tip, and remove the rod carefully. The microelectrode is placed almost horizontally (tip part being slightly upward) into a silica-gel-dried sealed container in the dark in order to avoid dust and preserve the quality of the cocktail. The cocktail is going to move upward to the tip by capillarity (you need to wait overnight at least).

Next day, the backfilling solutions can be added (usually just before use). The solutions are buffered at $\mathrm{pH} 6$ and comprise $0.3 \mathrm{M} \mathrm{KCl}, 0.01 \mathrm{M}$ TRIS/MES for $\mathrm{H}^{+}, \mathrm{KCl} 3 \mathrm{M}$ for $\mathrm{K}^{+}$et $\mathrm{KNO}_{3} 0.1 \mathrm{M}, \mathrm{KCl} 0.1 \mathrm{M}$ for $\mathrm{NO}_{3}{ }^{-}$. Before using the microelectrodes, we break the tip carefully in order to increase the tip diameter to $5 \mu \mathrm{m}$. It gives a better and faster response from the microelectrodes even if their lifetime is reduced. The microelectrodes are finished and ready for calibration.

\subsubsection{Calibration}

Ion-selective microelectrodes can be calibrated using concentration or activity; the electrodes actually respond to changes in activity. For these reasons, the calibration of microelectrodes generally uses solutions that match the extracellular environment which is going to be used during the measurements. In our case, the ion concentrations are low and the activity coefficient can be approximated to 1 . The ideal relationship between electrode output $(\mathrm{mV})$ and the concentration $(\mathrm{mM})$ of the ion under study is log-linear, and is described mathematically by the Nernst equation (see Sect. 5.2.1).

\subsubsection{Equipment Needed}

Salt solutions $\left(\mathrm{KNO}_{3}, \mathrm{CaSO}_{4}\right)$ and $\mathrm{pH}$ buffers $(5,6,7)$

Electrophysiology equipment (see Sect. 5.5)

$\mathrm{Ag} / \mathrm{AgCl}$ metal electrodes (in the base of the microelectrode holder)

First, chloride must be added on the surface of the silver rod in order to create a good electric connection. The silver rod is immersed into an $\mathrm{HCl} 0.1 \mathrm{M}$ bath while 
connected to a $1.5 \mathrm{~V}$ battery. A second silver rod in the solution ends the loop. The silver rod connected the positive side is recovered by a chloride coating.

When the $\mathrm{Ag} / \mathrm{AgCl}$ electrode is ready, place the microelectrode into its holder. Then, you need to dip the electrode into the "zero" solution, which is basal $\mathrm{CaSO}_{4}$ $0.2 \mathrm{mM}$ in our case (the $\mathrm{pH}$ electrode ends the loop). The voltage can be recorded (value 1). Then, we record the voltage values for $\mathrm{KNO}_{3} 0.05,0.25$ and $0.5 \mathrm{M}$ (values 2, 3 and 4). The data are plotted $\left(V=f c t \log _{10}\left[\mathrm{KNO}_{3}\right]\right.$ for $\mathrm{K}^{+}$and $\left.\mathrm{NO}_{3}{ }^{-}\right)$to get $y$-intercept and slope values. The slope of the linear regression should be close to $59 \mathrm{mV}$ for a perfect microelectrode at $25^{\circ} \mathrm{C}$. Microelectrodes can be discarded if the slope is less than $55 \mathrm{mV}$. However, as slopes are temperature-sensitive, always carry out the calibration at the same temperature as the measurement. For calibration of $\mathrm{pH}$ microelectrodes, a set of standard $\mathrm{pH}$ buffers can be used and simply checked with a $\mathrm{pH}$ meter.

\subsubsection{Microelectrode Selectivity}

In order to determine the selectivity of the microelectrodes produced, they were subjected to a gradient of ion concentration. In the following example (Fig. 5.6), the microelectrodes were immersed into an increasing concentration of $\mathrm{KNO}_{3}$ (from 1 $\mu \mathrm{M}$ to $0.1 \mathrm{M}$ ) with $\mathrm{CaSO}_{4} 0.2 \mathrm{mM}$ as background solution. The $\mathrm{pH}$ was set at 5.8 in each solution. The voltage values obtained at the voltmeter amplifier were plotted against the log values of the concentrations. The response of the microelectrode should be linear. The limit of detection is where the measurement shifts from the linear range. In our case, the detection limits for our $\mathrm{K}^{+}$and $\mathrm{NO}_{3}{ }^{-}$microelectrodes are between 1 and $10 \mu \mathrm{M}$. Our studies are therefore realised in a concentration range above $10 \mu \mathrm{M} \mathrm{KNO}_{3}$ in the solution.

The microelectrodes are ready for net ion flux measurements at the surface of the roots or mycorrhizal roots.

\subsection{Setting up the Electrophysiological Measurements}

The measurement of the ion net fluxes at the surface of the root is determined by (5.9), as described in Sect. 5.3 of this chapter, which is

$$
J=\frac{k\left(2 D / r^{2}\right)\left(\mathrm{C}_{2}-\mathrm{C}_{1}\right)}{\ln \left[\left(d_{2}+r\right) /\left(d_{1}+r\right)\right]} .
$$

With the microelectrodes, we measure the ion concentrations $C_{1}$ and $C_{2}$ at the distances $d_{1}$ and $d_{2}$ from the root surface. The radius of the root is determined by measuring the root diameter on the monitor linked to the camera. The conversion factor is known to translate into the actual root diameter, which is subsequently divided by two. The coefficients $k$ and $D$ are invariable in our conditions of 

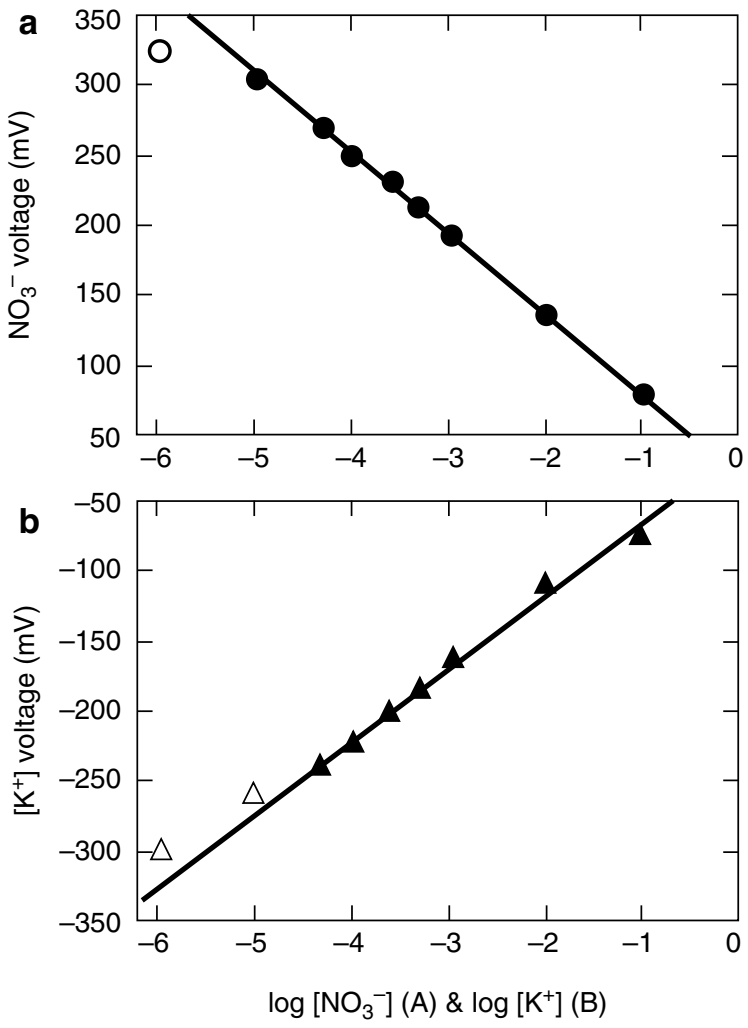

Fig. 5.6 Selectivity of the $\mathrm{NO}_{3}{ }^{-}$(a) and $\mathrm{K}^{+}$(b) microelectrodes. The microelectrodes were immersed in $\mathrm{CaSO}_{4} 0.2 \mathrm{mM}$ solutions containing increasing concentrations of $\mathrm{KNO}_{3}$. The potential values were then plotted vs the $\log$ [ion] in the solution. A linear regression was plotted on the points to determine the selectivity of the microelectrodes

experimentation. The only factors modifying the flux values are the distance from the root and the concentration (microelectrodes).

So, which distances from the root surface to choose?

And which parameters can affect the calculation of the ion concentrations?

\subsubsection{Determination of the Distances from the Root Surface for the Measurement Points}

\subsubsection{Concept of the Undisturbed Layer and the Ionic Gradient}

In our system, the woody seedling lies at the bottom of a small container (see Fig. 5.4). This small container has a solution entry on one side and a solution exit at the other side. The solution flows on top of the seedling and can be changed at 
any time (i.e. by increasing the ion concentration). The flow has to be small enough in order to replace the solution far away from the root without disturbing the solution layer at the surface of the root. The solution at the surface of the root does not flow, or does so at a negligible speed due to friction forces (like the wind with an object). The undisturbed layer size has to be determined using the microelectrodes and the net flux measurements have to occur in this undisturbed layer of solution.

In order to determine the size of the undisturbed layer, the microelectrodes were moved from 10 to $1,510 \mu \mathrm{m}$ with $100 \mu \mathrm{m}$ steps. In the undisturbed layer of solution, the ion concentrations form a linear gradient (Fig. 5.7). If the solution flow slowly increased from the root surface (no layer), the points would form a curve. The limit of the gradient can be calculated from the intersect between the final concentration and the slope of the gradient (Fig. 5.7).

Then, we measured the average distance at which the gradient disappears (Table 5.1) along the taproot of a Corsican pine seedling. The shortest distance from the root where the gradient disappeared was around $600 \mu \mathrm{m}$. Measurement along the root of maritime pine gave the same order of values (data not shown).

The limit of the gradient determined, two points in this radius are needed in order to determine the net flux. Of course, the distance between the two measurement points is important for the calculation of the net flux [ $d_{1}$ and $d_{2}$ in (5.9), Sect. 5.3.2]. The greater the distance, the greater the chance that a difference of concentrations can be detected. The larger the difference in concentration, the more accurate is the final value of the net flux.
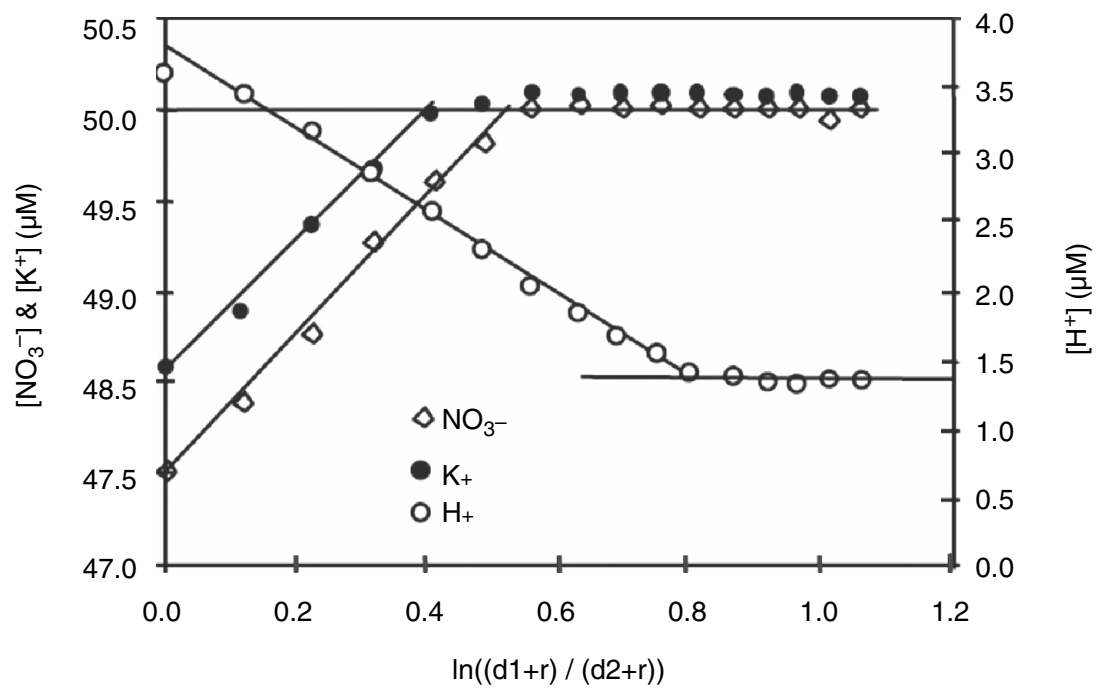

Fig. 5.7 Gradients of $\mathrm{NO}_{3}{ }^{-}, \mathrm{K}^{+}$and $\mathrm{H}^{+}$concentrations from the surface of the root $(\sim 0.01 \mathrm{~mm})$ to the bulk solution $(\sim 2 \mathrm{~mm})$ 


\subsubsection{What is the Distance from the Root to Choose?}

Our next task was to determine which distance from the root was right to determine the net fluxes. Of course, the points of measurement are localized in the undisturbed layer of solution $(<600 \mu \mathrm{m}$; Table 5.1). The distances 300, 400 and $500 \mu \mathrm{m}$ were tested all along the first $10 \mathrm{~mm}$ of the taproot of a Corsican pine seedling.

As shown in Fig. 5.8, the first 2 millimetres of the root provide a huge variation in the net flux measurement for all the microelectrodes. Thus, for $\mathrm{NO}_{3}{ }^{-}$, the values for $300 \mu \mathrm{m}$ are divergent from the values taken at 400 and $500 \mu \mathrm{m}$. For $\mathrm{H}^{+}$and $\mathrm{K}^{+}$, values are very similar to each other whatever the distance from the root. We can observe a huge efflux of $\mathrm{H}^{+}$at the tip of the pine root which reduces strongly after 1-2 $\mathrm{mm}$ from the apex. For $\mathrm{K}^{+}$, a strong efflux appears at $2 \mathrm{~mm}$ and reduces gradually towards $6 \mathrm{~mm}$ from the apex.

\subsubsection{Factors Affecting the Calculation of the Concentration}

The calculation of the ion concentration is determined by (5.4) described in Sect. 5.2.2 of this chapter, and this can be transformed to

$$
C_{\mathrm{e}}=C_{\mathrm{i}} \exp (-n F \Delta V / R T)
$$

Therfore, the potential at the microelectrode is the main factor to be studied. $C_{\mathrm{e}}$ can be $C_{1}$ and $C_{2}$ depending on the distance from the root surface. The microelectrodes have a time response to changes in the solution. Also, this time response is fast, making an average of the concentration over a short length of time when the potential values are stable more acceptable as a basis for calculating the concentration at a given distance.

Table 5.1 Size of the undisturbed layer and/or size of the gradient at the surface of the first $10 \mathrm{~mm}$ of the taproot of a Corsican pine seedling

\begin{tabular}{lll}
\hline & \multicolumn{2}{c}{ Size of the undisturbed layer $(\mu \mathrm{m})$} \\
\cline { 2 - 3 } Distance from the root tip $(\mathrm{mm})$ & $\mathrm{NO}_{3}{ }^{-}$ & $\mathrm{K}^{+}$ \\
\hline 0.2 & $784 \pm 163$ & $822 \pm 203$ \\
1 & $813 \pm 149$ & $1,068 \pm 181$ \\
2 & $645 \pm 121$ & $716 \pm 129$ \\
3 & $853 \pm 213$ & $837 \pm 170$ \\
4 & $762 \pm 183$ & $729 \pm 278$ \\
5 & $1,086 \pm 201$ & $744 \pm 174$ \\
7 & $758 \pm 183$ & $602 \pm 116$ \\
10 & $1,284 \pm 107$ & $1,179 \pm 302$ \\
Average & $879 \pm 79$ & $837 \pm 73$ \\
\hline
\end{tabular}




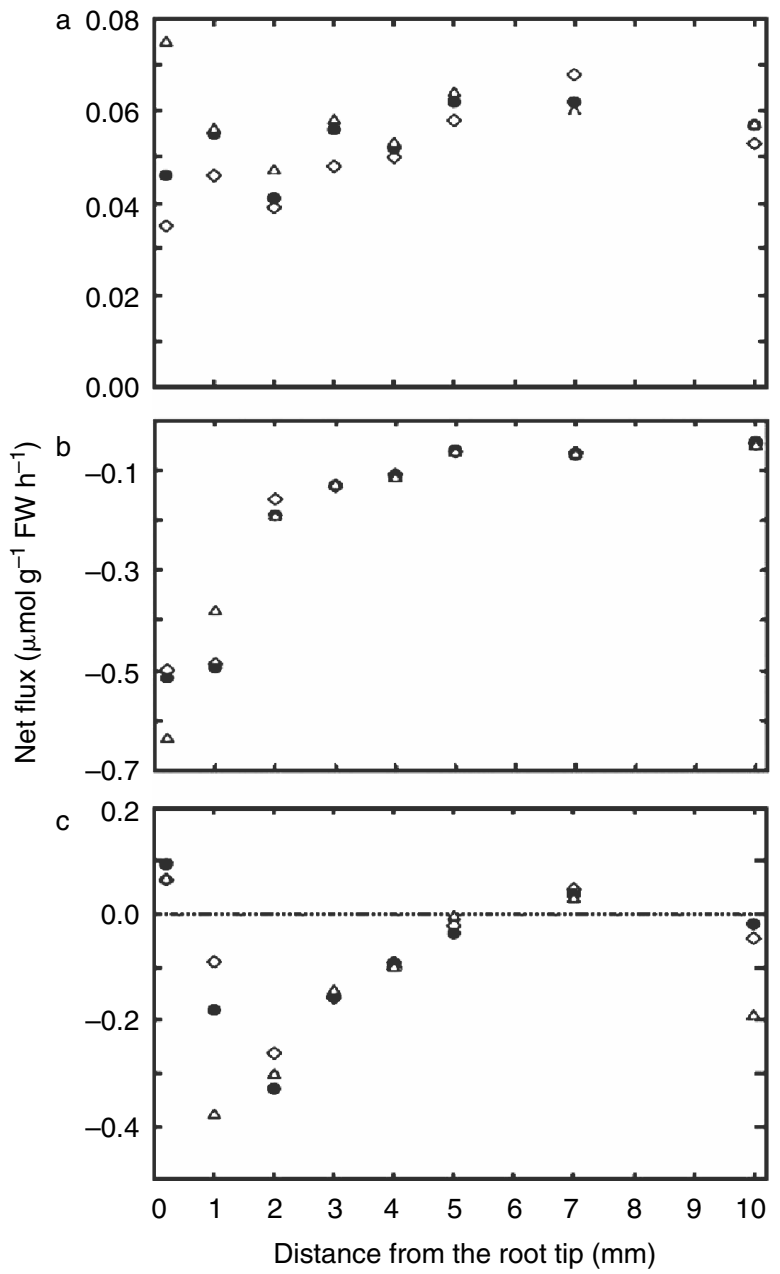

Fig. 5.8 Net ion fluxes of $\mathrm{NO}_{3}{ }^{-}$(a), $\mathrm{H}^{+}$(b) and $\mathrm{K}^{+}$(c) determined from measurement points $10-310 \mu \mathrm{m}$ (diamonds), $410 \mu \mathrm{m}$ (filled circles) or $510 \mu \mathrm{m}$ (triangles) along the first $10 \mathrm{~mm}$ of the taproot of a Corsican pine seedling

\subsubsection{Setting up the Recording Program}

A stable voltage reading is needed at one given measurement point. In our calculation, we always take the average of several values (A in Fig. 5.9) at one point ( 2 in Fig. 5.9) and the average of four passages at one point (1-4 in Fig. 5.9).

From this chart, we can observe that the experimenter can increase the number of concentration values at each point and the number of passages at each point. If a discrepancy in the concentrations between the four point measurements appears, 


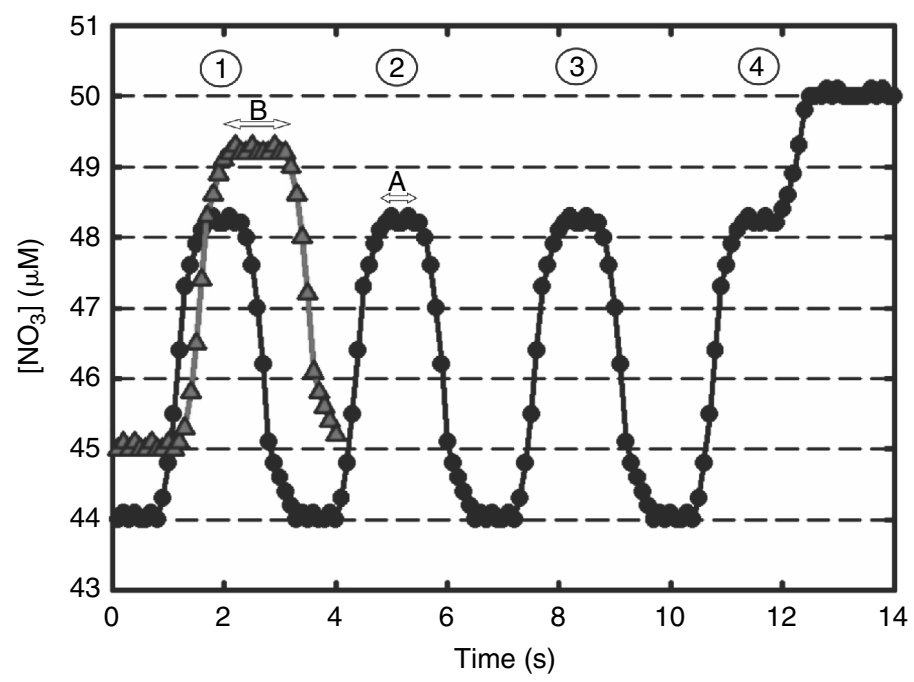

Fig. 5.9 Chart recording plotting the concentration vs time (each plateau correspond to a measurement point, here 10,410 and $2,010 \mu \mathrm{m})$. Closed circles: a full plot with a time of measurement $(A)$; grey triangles: a partial plot with a time of measurement $(B>A)$. In the full plot $(A)$, we can observe the four time measurements at $410 \mu \mathrm{m}$ from the root (labelled from 1 to 4 )

there is obviously something wrong (e.g. the microelectrode might have touched the root, creating a leakage from the broken cells at the surface of the root).

\subsubsection{Effect of the Recording Time on the Flux Calculation}

When small variations in the ionic concentrations are measured, a small error in the concentration difference $\left(C_{2}-C_{1}\right)$ results in a large variation in the net flux value $J$ (5.9). We tested two different durations of measurement at one point, 15 and $20 \mathrm{~s}$, when measuring $\mathrm{NO}_{3}{ }^{-}$and $\mathrm{K}^{+}$net fluxes at the surface of the first 10 millimetres of the taproot of a Corsican pine seedling (Fig. 5.10). Ion fluxes at the root surface of this species are usually smaller than for the maritime pine, and a variation in the concentration difference $\left(C_{2}-C_{1}\right)$ is surely going to affect the resulting net flux.

The ratios of the net $\mathrm{NO}_{3}{ }^{-}$(A) and $\mathrm{K}^{+}$(B) fluxes between 15 and $20 \mathrm{~s}$ are plotted in Fig. 5.10. The variations of $\mathrm{NO}_{3}{ }^{-}$net fluxes are generally low (except for one point) and the data are not significantly different from one another, indicating that increasing the recording time did not improve the flux calculation. For $\mathrm{K}^{+}$, we always observed a large variation of ion fluxes which probably explains the large variation of ratios shown in Fig. 5.10b. These variations could be due to a periodicity in intensity at one given point along the root, as shown in maize roots for $\mathrm{H}^{+}$and $\mathrm{Ca}^{2+}$ (Shabala et al. 1997). Also, we noticed that $\mathrm{K}^{+}$microelectrodes have a much shorter life than $\mathrm{H}^{+}$or $\mathrm{NO}_{3}{ }^{-}$microelectrodes, hours $\left(\mathrm{K}^{+}\right)$compared with days $\left(\mathrm{H}^{+}\right.$and $\left.\mathrm{NO}_{3}{ }^{-}\right)$. 


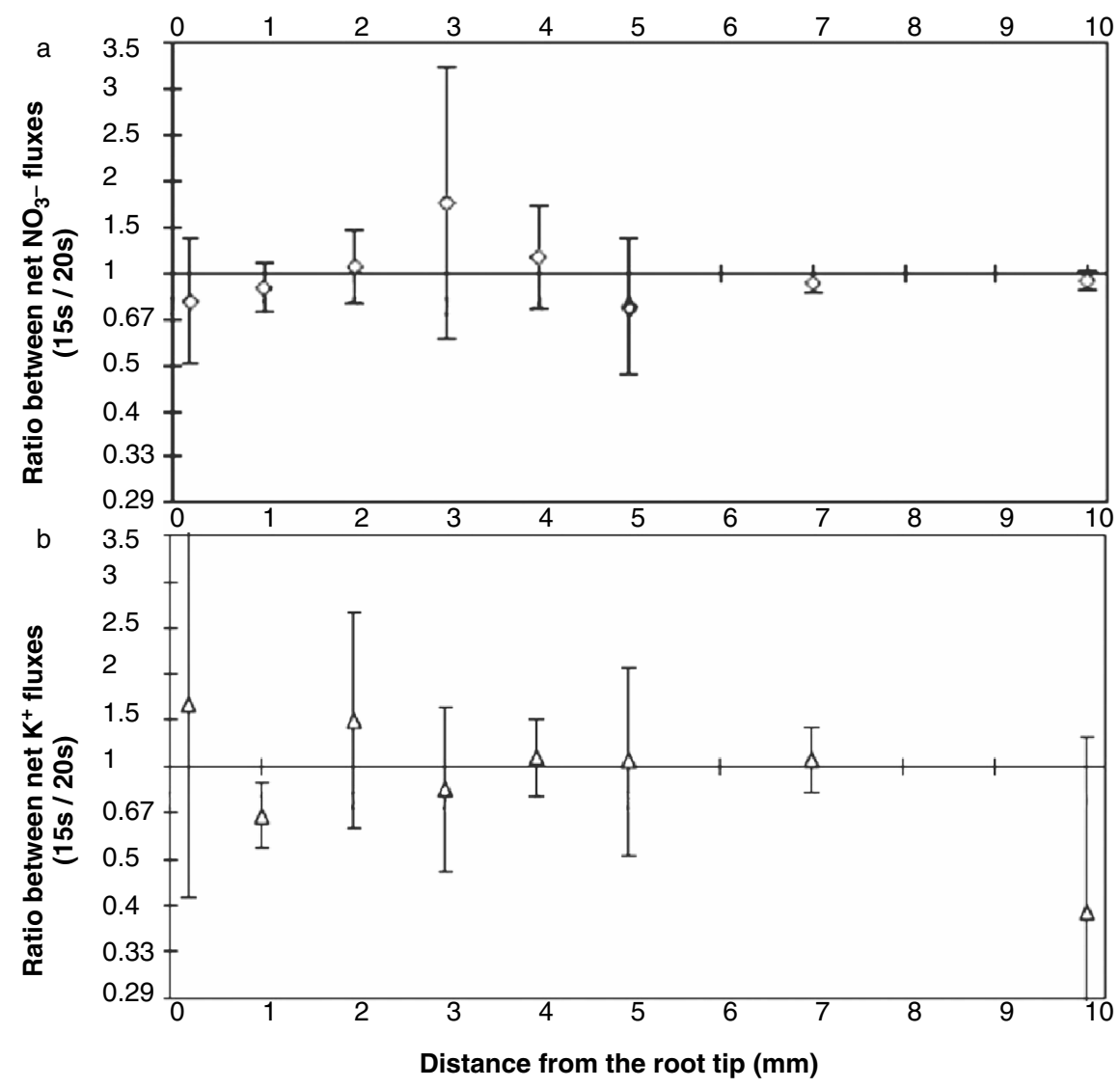

Fig. 5.10 Effect of the duration of the measurement (15 or $20 \mathrm{~s})$ on the calculation of the $\mathrm{NO}_{3}{ }^{-}$(a) and $\mathrm{K}^{+}$(b) net fluxes. The values are expressed as the ratio between the values obtained with a 15 -s step and the values obtained with a 20-s step as a function of the distance from the root tip of the Corsican pine seedling

Obviously, the longer the duration at one point, the more accurate should be the average of the potential values at this point but this matter has to be tested at least once for an experience condition given for the different type of microelectrode used.

\subsubsection{Using a Complex Perfusing Solution}

In our system, we always use a simple perfusing solution containing $\mathrm{CaSO}_{4} 0.2$ $\mathrm{mM}$, and then we add the required concentration of $\mathrm{KNO}_{3}$ (in order to measure the $\mathrm{H}^{+}, \mathrm{NO}_{3}{ }^{-}$and $\mathrm{K}^{+}$net fluxes). Of course, we have tested the effect of the $\mathrm{pH}$ on the responses of the $\mathrm{NO}_{3}{ }^{-}$and $\mathrm{K}^{+}$microelectrodes (data not shown). Extreme 
$\mathrm{pH}$ affects the responses, but our solutions are always set around 5.8-6. If other salts have to be added to the perfusing solution, the response of the microelectrodes to these additional ions has to be tested and the microelectrode should be calibrated in a solution containing these additional ions.

\subsection{A Case Study: Measurement of $\mathrm{NO}_{3}{ }^{-}$Net Fluxes into Ectomycorrhizal Short Roots}

\subsubsection{Validation of Flux Measurements into Coniferous Plants}

When using ion-selective microelectrodes for measuring net fluxes occurring into the roots, one of the main problems is to find some ways to evaluate the validity of this methodology. We did this in young maritime pine seedlings exhibiting only one main tap root (Plassard et al. 2002). These non-mycorrhizal young roots exhibited highly differentiated root zones together with highly different nitrate and potassium net fluxes measured using ion-selective microelectrodes. Potassium net uptake was characterised by a maximum net influx in the subapical zone (the "pink" zone), together with a high net efflux or no net flux occurring in the first millimetres of apex and in the browning zone far away from the apex, respectively. Nitrate net uptake was also maximal in the subapical root zone, but no net efflux was observed in the apical part, and low values of net influx were measurable in the browning root zone (Plassard et al. 2002). To validate these local measurements we measured nitrate and potassium uptake by the whole seedlings incubated in the same conditions using conventional methods (bulk medium depletion). The net uptake rates calculated from the integration of net ion fluxes with microelectrodes were found to be remarkably similar to those calculated from medium depletion (Fig. 5.11), validating our measurement conditions.

Another validation of this methodology was obtained at the level of ectomycorrhizal short roots and ${ }^{15} \mathrm{~N}$ accumulation in Pinus pinaster plants associated with the

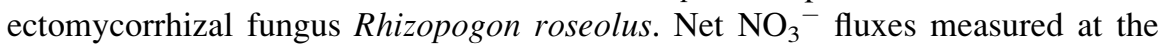
surface of $R$. roseolus mycorrhizal short roots were twice as high as those measured at the surface of non-mycorrhizal short roots in plants incubated with a flowing solution containing $\mathrm{KNO}_{3} 50 \mu \mathrm{M}$ (Gobert and Plassard 2007). This enhancement of $\mathrm{NO}_{3}{ }^{-}$uptake into mycorrhizal roots was confirmed by incubating $\mathrm{NM}$ and $\mathrm{M}$ plants for $6 \mathrm{~h}$ in a solution containing ${ }^{15} \mathrm{NO}_{3}{ }^{-} 50 \mu \mathrm{M}$. In these conditions, the ${ }^{15} \mathrm{~N}$ rates measured were $1.2 \pm 0.2$ and $0.7 \pm 0.15 \mu \mathrm{mol}{ }^{15} \mathrm{NO}_{3}{ }^{-} \mathrm{g}^{-1}$ root dry. $\mathrm{wt} \mathrm{h}^{-1}$, respectively, in $\mathrm{M}$ and $\mathrm{NM}$ plants. Total amounts of ${ }^{15} \mathrm{~N}$ measured in mycorrhizal plants were linearly correlated with the concentration of ergosterol, a sterol extracted from living fungal cells (Fig. 5.12). The contribution of ectomycorrhizal roots to the total uptake of ${ }^{15} \mathrm{NO}_{3}{ }^{-}$into the intact plants was then calculated from the value of the slope of the linear regression fitted to these data. This contribution was estimated to be $2.5 \mu \mathrm{mol}{ }^{15} \mathrm{NO}_{3}^{-}$accumulated $\mathrm{mg}^{-1}$ of ergosterol ${ }^{-1}$ whereas 

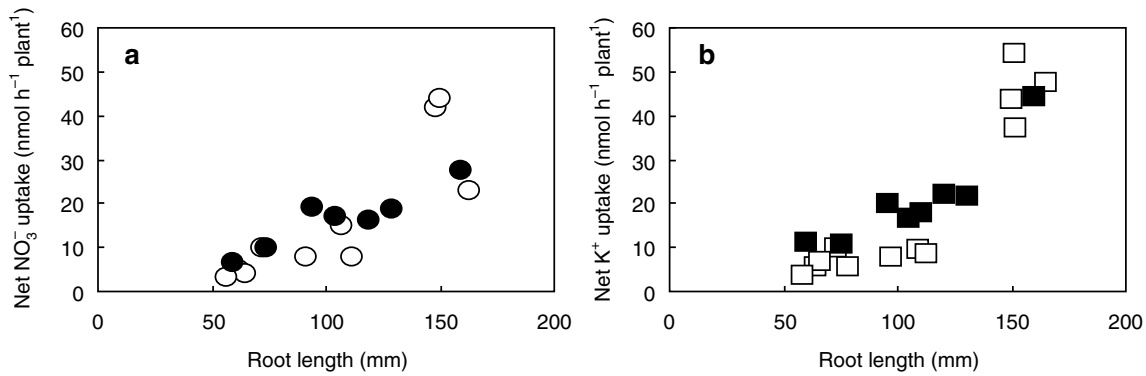

Fig. 5.11 Net uptake rates of $\mathrm{NO}_{3}{ }^{-}$(a) and $\mathrm{K}^{+}$(b) determined in whole roots of young nonmycorrhizal $P$. pinaster. Three-week-old plants presenting only one root, whose length varied from $c .50$ to $c .160 \mathrm{~mm}$, were incubated in a solution containing $0.2 \mathrm{mM} \mathrm{CaSO}_{4}$ and $20 \mu \mathrm{M} \mathrm{KNO}_{3}$ ( $\mathrm{pH}$ 5.7). Uptake rates were measured either from ion depletion from the medium (open symbols) or using ion-selective microelectrodes (closed symbols). In the latter case, local flux data obtained along the root were integrated over the whole root length to obtain net uptake rates per plant (redrawn from Plassard et al. 2002, with permission from Blakwell Publishing)

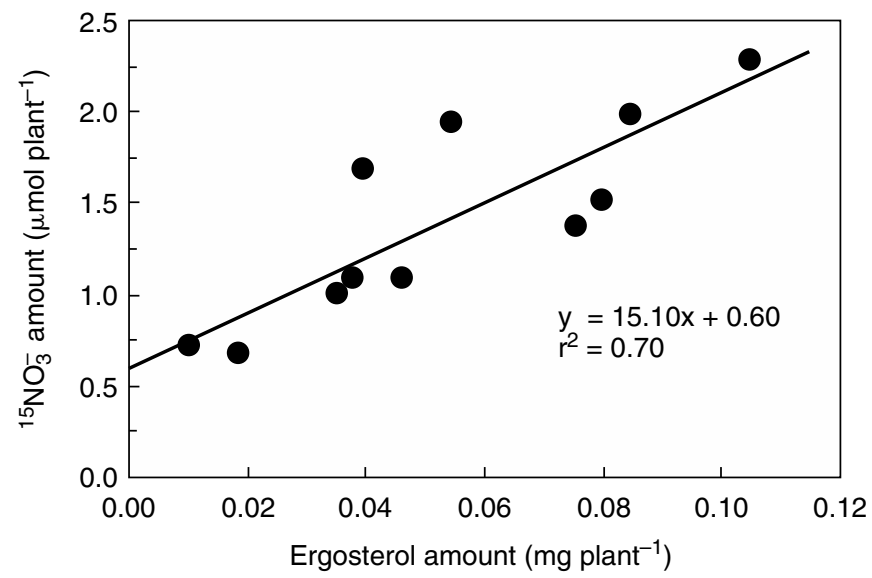

Fig. 5.12 Relationship between root ergosterol and total ${ }^{15} \mathrm{~N}$ amounts measured in $P$. pinaster associated with the ectomycorrhizal fungus $R$. roseolus. The plants were pre-incubated for 3 days in $1 \mathrm{mM} \mathrm{NO}_{3}{ }^{-}$solution before incubation for $6 \mathrm{~h}$ into the labelling solution containing $50 \mu \mathrm{M}$ ${ }^{15} \mathrm{KNO}_{3}$. The linear regression fitted to the points was highly significant $(P=0.0012)$ (redrawn from Gobert and Plassard 2007, with permission from Blackwell Publishing)

the contribution of the remaining root system was calculated to be $0.6 \mu \mathrm{mol}{ }^{15} \mathrm{NO}_{3}{ }^{-}$ per plant or $0.5 \mu \mathrm{mol}{ }^{15} \mathrm{NO}_{3}{ }^{-} \mathrm{g}^{-1}$ root dry. wt $\mathrm{h}^{-1}$ (the $y$-intercept). The $\mathrm{NO}_{3}{ }^{-}$ uptake rate into ectomycorrhizal roots $\left(V, \mu \mathrm{mol} \mathrm{NO}_{3}{ }^{-} \mathrm{g}^{-1} \mathrm{f} \mathrm{wt} \mathrm{h}^{-1}\right)$ was thus calculated using the equation:

$$
V=(v E)(F)
$$


where $v$ is the uptake rate per unit of ergosterol $\left(\mu \mathrm{mol} \mathrm{NO}{ }^{-} \mathrm{mg}^{-1}\right.$ ergosterol h$\left.{ }^{-1}\right)$, $E$ is the average concentration of ergosterol in the fungus in pure culture $(0.34 \mathrm{mg}$ $\mathrm{g}^{-1} \mathrm{f}$ wt, Plassard, unpublished data) and $F$ is the percentage of fungal tissue in ectomycorrhizal roots (62\%, Plassard et al. 2002). Using the parameters in the above equation, the estimated value of $\mathrm{NO}_{3}{ }^{-}$uptake rate into mycorrhizal short roots was calculated to be $0.53 \mu \mathrm{mol} \mathrm{NO}{ }_{3}^{-} \mathrm{g}^{-1} \mathrm{f} \mathrm{wt} \mathrm{h}{ }^{-1}$, a value that was very close to the one measured with an ion-selective microelectrode that was $0.6 \mu \mathrm{mol}$ $\mathrm{NO}_{3}{ }^{-} \mathrm{g}^{-1} \mathrm{f} \mathrm{wt} \mathrm{h}^{-1}$ (Gobert and Plassard 2007).

\subsubsection{Variation of $\mathrm{NO}_{3}{ }^{-}$Net Fluxes into Ectomycorrhizal Short Roots: Effect of $N$ Source Supplied to the Plants}

Several studies have indicated that $\mathrm{NO}_{3}{ }^{-}$uptake by forest trees and their fungal partners may be affected differently by variable conditions of $\mathrm{NO}_{3}{ }^{-}$availability that can occur in natural conditions, e.g. temporary variations of soil nitrate or ammonium concentrations and their ratios. We addressed this question by carrying out a comparative study of $\mathrm{NO}_{3}{ }^{-}$uptake induction under various conditions, with or without $\mathrm{NH}_{4}{ }^{+}$supplied at 50 and $500 \mu \mathrm{M}$, two concentrations close to the actual $\mathrm{N}$ level in forest soil. For this study, we used $P$. pinaster plants, whether associated or not with the ectomycorrhizal basidiomycete $R$. roseolus. Three-month-old plants were pre-incubated without nitrogen for 7 days ( $-\mathrm{N}$ plants) and then 3 days with $50 \mu \mathrm{M} \mathrm{NO}_{3}{ }^{-}\left(+\mathrm{NO}_{3}{ }^{-}\right)$with or without 50 or $500 \mu \mathrm{M} \mathrm{NH}_{4}{ }^{+}\left(+\mathrm{NH}_{4}{ }^{+} 50,+\mathrm{NH}_{4}{ }^{+}\right.$ 500 ) before net $\mathrm{NO}_{3}{ }^{-}$flux measurements. We applied $\mathrm{NO}_{3}{ }^{-}$concentrations ranging from 0 to $500 \mu \mathrm{M}$ as $\mathrm{KNO}_{3}$ in the flowing solution. Depending on the pre-incubation solution, we obtained different kinetics in non-mycorrhizal- and mycorrhizal short roots (Gobert and Plassard 2007). As shown in Table 5.2, which gives a summary of the values of apparent maximal net flux $\left(J_{\max }\right)$ and affinity $\left(\kappa_{\mathrm{m}}\right)$ calculated from these kinetics, nitrate net fluxes into non-mycorrhizal short roots from $\mathrm{N}$-starved plants were very low. In these conditions, the measurement of $\mathrm{NO}_{3}{ }^{-}$net fluxes presented a limit, since it was not possible to measure low fluxes at high external ion concentrations. Indeed, the voltage difference measured between the solution and the root becomes very low in these conditions (Gobert and Plassard 2007). Given the precision of the reading on the amplifier $(0.1 \mathrm{mV})$, we chose to calculate flux values when the average voltage difference was higher than $0.5 \mathrm{mV}$. This situation was encountered again when plants, whether mycorrhizal or not, were incubated with high $\mathrm{NH}_{4}{ }^{+}$concentration $(500 \mu \mathrm{M})$. However, measurement of $\mathrm{NO}_{3}{ }^{-}$net fluxes with $\mathrm{NO}_{3}{ }^{-}$selective microelectrodes enabled us to show that a complex kinetic process was occurring in non-mycorrhizal short roots fully induced for $\mathrm{NO}_{3}{ }^{-}$uptake, resulting in different values of apparent $J_{\max }$ and affinity $\kappa_{\mathrm{m}}$ (Table 5.2). In contrast, mycorrhizal short roots always displayed higher $\mathrm{NO}_{3}{ }^{-}$net fluxes than non-mycorrhizal short roots, together with simple kinetics (Table 5.2). Nevertheless, both types of short roots exhibited the same sensitivity to the $\mathrm{NH}_{4}{ }^{+}$ 
Table 5.2 Apparent values of $J_{\max }$ and $\kappa_{\mathrm{m}}$ for $\mathrm{NO}_{3}{ }^{-}$uptake of $-\mathrm{N},+\mathrm{NO}_{3}{ }^{-}$and $+\mathrm{NH}_{4}{ }^{+}$pretreated $P$. pinaster seedlings, whether associated or not with the ectomycorrhizal basidiomycete $R$. roseolus. Net $\mathrm{NO}_{3}{ }^{-}$fluxes were measured using $\mathrm{NO}_{3}{ }^{-}$selective microelectrodes placed at the surface of non-mycorrhizal short roots (NMSR) of non-inoculated plants or mycorrhizal short roots (MSR) of inoculated plants. The plants (3 months old) were pre-incubated without nitrogen for 7 days (-N plants) and then 3 days with $50 \mu \mathrm{M} \mathrm{NO}_{3}{ }^{-}\left(+\mathrm{NO}_{3}{ }^{-}\right)$with or without 50 or $500 \mu \mathrm{M}$ $\mathrm{NH}_{4}{ }^{+}\left(+\mathrm{NH}_{4}{ }^{+} 50,+\mathrm{NH}_{4}{ }^{+} 500\right)$ before net $\mathrm{NO}_{3}{ }^{-}$flux measurements. Parameters are given \pm confidence interval at $P=0.05(n \geq 6)$ and with $P$ value of the determination (from Gobert and Plassard 2007, with permission from Blackwell Publishing)

\begin{tabular}{|c|c|c|c|c|c|}
\hline Pre-treatment & $\begin{array}{l}\text { Short root } \\
\text { type }\end{array}$ & $\begin{array}{l}{\left[\mathrm{NO}_{3}{ }^{-}\right] \text {range }} \\
(\mu \mathrm{M})\end{array}$ & $\begin{array}{l}J_{\max }\left(\mu \mathrm{mol} \mathrm{g}^{-1}\right. \\
\left.\text { root fr. } \mathrm{wt} \mathrm{h} \mathrm{h}^{-1}\right)\end{array}$ & $\kappa_{\mathrm{m}}(\mu \mathrm{M})$ & $r^{2}$ \\
\hline \multirow[t]{4}{*}{$-\mathrm{N}$} & NMSR & $0-70$ & $0.29 \pm 0.02$ & $20 \pm 2.9$ & 0.99 \\
\hline & $P$ & & $<0.0001$ & $<0.0001$ & \\
\hline & MSR & $0-500$ & $1.32 \pm 0.07$ & $33 \pm 6.7$ & 0.99 \\
\hline & $P$ & & $<0.0001$ & $<0.0001$ & \\
\hline \multirow[t]{6}{*}{$+\mathrm{NO}_{3}{ }^{-}$} & NMSR & $0-70$ & $0.54 \pm 0.08$ & $21 \pm 6.7$ & 0.98 \\
\hline & $P$ & & $<0.0001$ & $<0.0001$ & \\
\hline & & 70-200 & $1.17 \pm 0.29$ & $111 \pm 58$ & 0.97 \\
\hline & $P$ & & $<0.0001$ & 0.0034 & \\
\hline & MSR & $0-500$ & $1.48 \pm 0.04$ & $82 \pm 6.7$ & 0.99 \\
\hline & $P$ & & $<0.0001$ & $<0.0001$ & \\
\hline \multirow[t]{6}{*}{$+\mathrm{NH}_{4}{ }^{+} 50$} & NMSR & $0-70$ & $0.39 \pm 0.08$ & $20 \pm 8.5$ & 0.99 \\
\hline & $P$ & & 0.0002 & 0.0136 & \\
\hline & & 70-200 & $0.75 \pm 0.22$ & $73 \pm 58$ & 0.83 \\
\hline & $P$ & & 0.0007 & 0.0416 & \\
\hline & MSR & $0-500$ & $2.1 \pm 0.22$ & $117.5 \pm 33$ & 0.97 \\
\hline & $P$ & & $<0.0001$ & $<0.0001$ & \\
\hline \multirow[t]{4}{*}{$+\mathrm{NH}_{4}{ }^{+} 500$} & NMSR & $0-100$ & $0.36 \pm 0.09$ & $57 \pm 14$ & 0.99 \\
\hline & $P$ & & $<0.0001$ & 0.0003 & \\
\hline & MSR & $0-100$ & $0.35 \pm 0.09$ & $66 \pm 29$ & 0.99 \\
\hline & $P$ & & $<0.0001$ & 0.0021 & \\
\hline
\end{tabular}

supply, with a decreasing effect appearing only with high $\mathrm{NH}_{4}{ }^{+}$supply (Table 5.2). Taken together, these measurements showed us that the regulation of nitrate uptake into the host plant and its ectomycorrhizal fungus could be different. This also strongly suggests that the ectomycorrhizal symbiosis could greatly help the plant to cope with changing $\mathrm{NO}_{3}{ }^{-}$availability in the soil, especially when it is low.

\subsection{Conclusions}

In this chapter we have described the technique of ion fluxes measurement outside the tissues in woody plants and ectomycorrhizal roots. We demonstrated that this technique could be a really powerful methodology to assess the actual role of ectomycorrhizal roots in highly heterogeneous root system. In our laboratory, we 
have made ion-selective microelectrodes only for three ions, but it is possible to extend the range of these microelectrodes to many other ions. However, among the numerous ionophores/cocktail solutions that are now available commercially, an ionophore for orthophosphate activities is still missing, despite recent papers on this topic (Wang and Bishop 2005; Zou et al. 2007). Indeed, the main problem of this anion is that its net valence ( $F$ in Nernst's equation) will depend on $\mathrm{H}^{+}$concentration in the solution, thus restricting its use to extremely well-defined $\mathrm{pH}$ conditions. Such $\mathrm{pH}$ stability will not be compatible with $\mathrm{pH}$ changes mediated by the root activity that will occur at the root surface. To us, the main advantage of the microelectrode technique is that net fluxes can be recorded for several hours, allowing the variation of ionic conditions of the flowing solution and the measurement of net fluxes at the same spot of the root. From an experimental point of view, its main limitation is the impossibility of measuring low fluxes at high external ion concentrations. However, it can be argued that in soil conditions, concentrations of available mineral nutrients will probably be most of the time in the range that can be used for measurements with ion-selective microelectrodes.

\section{References}

Ammann D (1986) Ion-selective microelectrodes. Principles, design and application. Springer, Berlin Heidelberg, p 346

Gobert A, Plassard C (2002) Differential $\mathrm{NO}_{3}{ }^{-}$-dependent patterns of $\mathrm{NO}_{3}{ }^{-}$uptake in Pinus pinaster, Rhizopogon roseolus and their ectomycorrhizal association. New Phytol 154: 509-516

Gobert A, Plassard C (2007) Kinetics of $\mathrm{NO}_{3}{ }^{-}$net fluxes in Pinus pinaster, Rhizopogon roseolus and their ectomycorrhizal association, as affected by the presence of $\mathrm{NO}_{3}{ }^{-}$and $\mathrm{NH}_{4}{ }^{+}$. Plant Cell Environ 30:1309-1319

Henriksen GH, Bloom AJ, Spanswick RM (1990) Measurement of net fluxes of ammonium and nitrate at the surface of barley roots using ion-selective microelectrodes. Plant Physiol 93:271-280

Henriksen GH, Raman DR, Walker LP, Spanswick RM (1992) Measurement of net fluxes of ammonium and nitrate at the surface of barley roots using ion-selective microelectrodes: II. Patterns of uptake along the root axis and evaluation of the Microelectrode Flux Estimation Technique. Plant Physiol 99:734-747

Huang JW, Shaff JE, Grunes DL, Kochian LV (1992) Aluminum effects on calcium fluxes at the root apex of aluminum-tolerant and aluminum-sensitive wheat cultivars. Plant Physiol 98:230-237

Kang TM, Markin VS, Hilgemann DW (2003) Ion fluxes in giant excised cardiac membrane patches detected and quantified with ion-selective microelectrodes. J Gen Physiol 121:325-47

Kochian LV, Shaff JE, Lucas WJ (1989) High affinity K uptake in maize roots: a lack of coupling with $\mathrm{H}^{+}$efflux. Plant Physiol 91:1202-1211

McClure PR, Kochian LV, Spanswick RM, Shaff JE (1990) Evidence for cotransport of nitrate and protons in Maize roots: II. Measurement of $\mathrm{NO}_{3}{ }^{-}$and $\mathrm{H}^{+}$fluxes with ion-selective microelectrodes. Plant Physiol 93:290-294

Miller AJ, Cookson SJ, Smith SJ, Wells DM (2001) The use of microelectrodes to investigate compartmentation and the transport of metabolized inorganic ions in plants. J Exp Bot 52:541-549

Newman IA (2001) Ion transport in roots: measurement of fluxes using ion-selective microelectrodes to characterize transporter function. Plant Cell Environ 24:1-14 
Newman IA, Kochian LV, Grusak MA, Lucas WJ (1987) Fluxes of $\mathrm{H}^{+}$and $\mathrm{K}^{+}$in corn roots: characterization and stoichiometries using ion-selective microelectrodes. Plant Physiol 84: $1177-1184$

Plassard C, Guerin-Laguette A, Very AA, Casarin V, Thibault JB (2002) Local measurements of nitrate and potassium fluxes along roots of maritime pine. Effects of ectomycorrhizal symbiosis. Plant Cell Environ 25:75-84

Shabala S, Newman I, Morris J (1997) Oscillations in $\mathrm{H}^{+}$and $\mathrm{Ca}^{2+}$ ion fluxes around the elongation region of corn roots and effects of external pH. Plant Physiol 113:111-118

Shabala L, Ross T, Newman I, McMeekin T, Shabala S (2001) Measurements of net fluxes and extracellular changes of $\mathrm{H}^{+}, \mathrm{Ca}^{2+}, \mathrm{K}^{+}$, and $\mathrm{NH}_{4}{ }^{+}$in Escherichia coli using ion-selective microelectrodes. J Microbiol Methods 46:119-29

Thain JF (1995) Electrophysiology. Methods Cell Biol 49:259-274

Wang JJ, Bishop PL (2005) Development of a phosphate ion-selective microelectrode and its use in studies of the enhanced biological phosphorus removal (EBPR) process. Environ Technol 26:381-388

Zou Z, Han J, Jang A, Bishop P, Ahn C (2007) A disposable on-chip phosphate sensor with planar cobalt microelectrodes on polymer substrate. Biosens Bioelectron 22:1902-1907 